\title{
BMJ Global Health A health systems resilience research agenda: moving from concept to practice
}

\author{
Dell D Saulnier (10 , ${ }^{1}$ Karl Blanchet (1) , ${ }^{2}$ Carmelita Canila, ${ }^{3}$ Daniel Cobos Muñoz,, 4 \\ Livia Dal Zennaro, ${ }^{6}$ Don de Savigny, ${ }^{4,5}$ Kara N Durski (D) , ${ }^{7,8}$ Fernando Garcia, ${ }^{3}$ \\ Pauline Yongeun Grimm, ${ }^{4}$ Aku Kwamie, ${ }^{9}$ Daniel Maceira, ${ }^{10,11}$ Robert Marten (D) ,6 \\ Isabelle Peytremann-Bridevaux, ${ }^{12}$ Camille Poroes, ${ }^{12}$ Valery Ridde (D),${ }^{13}$ \\ Laurence Seematter, ${ }^{12}$ Barbara Stern, ${ }^{11}$ Patricia Suarez, ${ }^{11}$ Gina Teddy, ${ }^{14}$ \\ Didier Wernli (1) , ${ }^{15}$ Kaspar Wyss, ${ }^{4,5}$ Fabrizio Tediosi (i) ${ }^{4,5}$
}

\begin{abstract}
To cite: Saulnier DD, Blanchet K, Canila C, et al. A health systems resilience research agenda: moving from concept to practice. BMJ Global Health 2021;6:e006779. doi:10.1136/ bmjgh-2021-006779
\end{abstract}

Handling editor Seye Abimbola

Received 30 June 2021 Accepted 20 July 2021
Check for updates

\section{(C) Author(s) (or their} employer(s)) 2021. Re-use permitted under CC BY-NC. No commercial re-use. See rights and permissions. Published by BMJ.

For numbered affiliations see end of article.

Correspondence to Dr Fabrizio Tediosi; fabrizio.tediosi@unibas.ch

\section{ABSTRACT}

Health system resilience, known as the ability for health systems to absorb, adapt or transform to maintain essential functions when stressed or shocked, has quickly gained popularity following shocks like COVID-19. The concept is relatively new in health policy and systems research and the existing research remains mostly theoretical. Research to date has viewed resilience as an outcome that can be measured through performance outcomes, as an ability of complex adaptive systems that is derived from dynamic behaviour and interactions, or as both. However, there is little congruence on the theory and the existing frameworks have not been widely used, which as diluted the research applications for health system resilience. A global group of health system researchers were convened in March 2021 to discuss and identify priorities for health system resilience research and implementation based on lessons from COVID-19 and other health emergencies. Five research priority areas were identified: (1) measuring and managing systems dynamic performance, (2) the linkages between societal resilience and health system resilience, (3) the effect of governance on the capacity for resilience, (4) creating legitimacy and (5) the influence of the private sector on health system resilience. A key to filling these research gaps will be longitudinal and comparative case studies that use cocreation and coproduction approaches that go beyond researchers to include policy-makers, practitioners and the public.

\section{INTRODUCTION}

In the last decade, resilience has emerged as a key concept for health systems in global health. ${ }^{1}$ Building on work from other disciplines, health systems resilience is generally understood as the capacity of a system to absorb, adapt or transform in order to maintain essential functions when faced with shocks and stresses. ${ }^{2-4}$ The COVID-19 pandemic and ongoing conflicts have only heightened recognition of the importance of resilience, by profoundly challenging health systems worldwide to cope with and adapt to new circumstances. ${ }^{5}$ Resilience has

\section{Summary box}

- Improving resilience could help health system responses to shocks like COVID-19, but the research has so far remained primarily theoretical. In order to develop and implement strategies to strengthen systems, we need to conduct applied research towards a cohesive set of goals.

- Resilience can be critiqued for its potential for political misuse, returning to vulnerability and putting burden to cope with shocks back on the community. If these issues are correctly addressed during research and interpretation of findings, resilience can be an innovative way to look at and strengthen health systems during the pandemic and future shocks and stresses.

- To identify where to invest future research time and resources for the greatest payoff, we established five priority areas for health system resilience research from discussion with global experts: (1) measuring and managing dynamic performance, (2) linking societal and health system resilience, (3) governing for resilience, (4) legitimacy and (5) the influence of private and voluntary sectors on resilience.

- A key to filling these research gaps will be longitudinal and comparative case studies that use cocreation and coproduction approaches that go beyond researchers to include policy-makers, practitioners and the public.

ushered in a new perspective on how health systems can adjust to shocks and maintain essential services. Yet to date, research and discussions around health systems resilience have focused on theory and principles; the concept is still nascent in health policy and system research. ${ }^{6}$ Although research methodologies are recognised, applied research on how resilience is created or strengthened in health systems-a crucial step to developing strategies to promote resilience-remains limited. ${ }^{7}$ As we have seen with COVID-19, strong debates continue around the most 
effective, equitable and efficient way for health systems to be prepared for and respond to such a public health shock, from testing strategies, vaccination approaches, to regulation of medical products and devices, to restructuring health service delivery, to the depth and breadth of lockdown measures. While health system responses to COVID-19 must be relevant to their specific context, the pandemic has made it clear that health system stakeholders are searching for and trying to adopt informed strategies, ideas and plans that can guide their decision making. How do we move health systems resilience research from the concept to practice?

\section{RESILIENCE AS AN ABILITY}

The jump from conceptual to research with operational implications requires considering different starting points of health systems resilience and the critiques of resilience. The complexity of conceptual differences has been well covered ${ }^{6}{ }^{6}$ but a fundamental distinction remains: is resilience viewed as an outcome, an ability or both? Biddle $e t a l^{8}$ found that research that views resilience as an outcome is predominantly quantitative, working under the assumption that resilience can be measured and indexed, and that measuring variation in such outcomes will identify inputs that can improve the system. ${ }^{8}$ In complement, Topp ${ }^{9}$ notes that one implication of expressing resilience capability as an outcome is that resilience is seen as 'an uncomplicated, even monolithic 'good': a goal synonymous with optimised performance'. ${ }^{9}$ If resilience is only seen as a performance objective and absorptive, adaptive and transformative change are seen as inherently positive, we are prone to overlook the broader economic, historical, sociocultural and political contextual realities within which health systems are embedded. It risks enacting-or declining to enact-change as its own goal, without greater consideration of whether equity, effectiveness, efficiency and sustainability will follow. ${ }^{10}{ }^{11}$ Resilience requires the ability to adapt; change is partial to the underlying objectives, values, and inequalities that exist in a health system and its context. Health systems resilience has already been criticised for ignoring issues of responsibility, politics and power. Reducing resilience to indicators only favours a 'return to normality', one which can sustain a state of vulnerability without addressing the underlying causes that created the vulnerability in the first place. ${ }^{912}$ It can also fail to recognise the dynamics of health systems, the absorption, adaptation, and transformation constantly taking place within patient, management and clinical regulation and practice and other interlinked systems, pushing the responsibility to cope and adapt back solely onto populations, increasing their vulnerability. ${ }^{1314}$

Acknowledging a system's local context, interconnectedness and circumstances requires reframing resilience as an ability as well. This second perspective is in line with the idea of health systems as complex adaptive systems constantly emerging, self-organising and adapting to change ${ }^{15}$ Considering health systems as complex adaptive systems is useful for understanding what gives systems the capacity to absorb, react, adapt or transform to different kinds of shocks, rather than what attributes the system has. ${ }^{2}$ Health systems are shaped by the variety of interactions and decisions that various actors, such as patients, carers, community health workers, general public, healthcare professionals, managers, policy-makers and private companies, are able or willing to take, governed by implicit and explicit rules. ${ }^{3}$ These interactions and rules hinge on the people, their mindsets, interests and agency, as well as the power structures within a health system's context; resilience as an ability depends on these interdependent relationships. In addition, resilient people and communities are a foundation for resilient systems to function optimally. Resilience from this point of view enables consideration of how to strengthen health systems and deliver equitable, efficient, responsive and sustainable health services and outcomes for both everyday benefits and when faced with shocks such as the COVID-19 pandemic, climate crises and future, unforeseen emergencies. However, this perspective has so far primarily been the domain of qualitative methods, used to make sense of capacities, relationships between actors of the system and dynamics in a given context. ${ }^{8}$ Describing resilience as both an outcome and an ability allows for resilient systems to be viewed with a broader scope and recognises the additional dynamics and complexities that need to be understood and researched.

\section{A HEALTH SYSTEMS RESILIENCE RESEARCH AGENDA TO PROMOTE ACTION}

We believe health systems resilience research has today reached a crucial point. The weak convergence on clear, comprehensive health system resilience definitions, plus limited operationalisation of the existing frameworks, has diluted research applications and inhibited the development of a common understanding. If these differences remain fractured without a clear common goal, we risk losing the momentum to follow the conceptual inroads with concrete applications. This echoes the case of systems thinking for health systems strengthening. Calls to move towards systems thinking approaches for health system interventions have only partly been followed by empirical research and concrete applications. ${ }^{16}$ The crux of the issue is this: if we ultimately want to create more resilient health systems, where, when and how do we invest our research resources for the greatest impact?

In March 2021, we convened a global group of health system researchers to address this fundamental question and initiate a research agenda for health system resilience. Prior to meeting, the authors Saulnier et al conducted a scoping review and analysis of the health system resilience literature, with two focus points: (1) to assess our current understanding of resilience by examining published discussions and debates on resilience and COVID-19 and (2) to summarise the current state of methods used for empirical health systems research and gaps in application. ${ }^{17}$ With that review as a starting point, we discussed as a group the following questions in 
the workshop: Using what we have learnt from COVID-19 and other health emergencies, what are the priorities for health system resilience research? How should research on health systems resilience be implemented?

Based on the workshop discussions and the diverse experiences of the participants, we propose a research agenda for health system resilience that embraces complexity and recognises the embedding of health intrarelated systems in the broader sociocultural, economic and political environment. ${ }^{18}$ Below, we offer five key research areas for health systems resilience and discuss approaches to implementing resilience research.

\section{How should systems dynamic performance be managed and measured?}

Resilience requires seeing health systems as complex adaptive systems fundamentally embedded within and linked to multiple other systems. Health systems both influence and are influenced by the global markets, ethics and values, political systems, and social protection systems, among others, all of which shape people's health. COVID-19 is an illustrative example: the health system's ability to manage health needs has had a clear impact on other systems (eg, labour, economy, the environment), while the ability of other systems to protect health has in turn altered the health system's capacity to manage. Ignoring these interlinkages will lead to simplistic, short-term solutions that may be costly, ineffective or inappropriate when implemented across contexts, at differing levels, or in the wake of societal shifts like COVID-19. If we want to develop systems capable of continuous change and adaptation, we need to recognise and incorporate other systems and contexts as determinants of resilience.

To connect health system resilience to other systems, our measures of resilience need to move beyond health service delivery functions in response to shocks. Alternative measures of multi-system performance for health during crises, such as financial and health equity-related outcomes, should be explored. Assessing how the health system influences and is influenced by other sectors like travel and trade, food security, education, social protection can generate knowledge on 'what works' in a given context. If we can identify measures of resilience that address dynamism (eg, change in social networks, fluidity of information circulation within the system), we can begin to distinguish cross-system resilience capacities. There is potential to learn by documenting local experiences to different risks and their effects on health and other systems, which can reduce traditional biases around contextual factors like managerial skills and power.

\section{To what degree and in what ways does societal resilience support health system resilience? What are the key leverage points?}

Health systems do not stop at formal systems; they include communities, families, lay workers and informal providers who manage their own health and provide care during shocks and stresses. They are valuable sources of resilience capacity, coping strategies, resources and knowledge. Considering individuals, communities and societies as key drivers of resilience-from community driven ideas to research to cocreated systems strengthening initiatives-has the potential to increase the system's resilience capacity. The findings from the 2014 Ebola outbreak in West Africa are clear about the key role played by communities in responding to and containing the outbreak ${ }^{19-22}$; despite this, the empirical research conducted since is scarce. Research needs to further investigate how individual and community resilience contributes to and potentially hinders health systems resilience to identify joint capacities, limits and solutions.

\section{How does governance affect the capacity for resilience?}

Resilience relies on the system's ability to perform and to change when needed. Governance aims to drive the behaviour, priorities, interactions, participation, accountability and decisions of system actors; power influences the ways in which actors can participate in and contribute to governance. For instance, the most comprehensive surveillance system-necessary for preparedness, awareness of, and response to shocks-will only function if the people who make public health decisions collectively use it and respond to its warnings. While each shock or stress to a health system will be different, and each health system's context is unique, understanding the details of cross-cutting areas of governance and power can lead to practical ideas for changing practice and influencing leadership.

Although governance has been repeatedly noted in resilience research, we need to better understand the nuances of governance and resilience. ${ }^{23}$ This includes the influence of differing power, leadership dynamics and governance contexts (eg, highly bureaucratic, hierarchical, autocratic) on the system's ability to absorb, adapt or transform. Resilience may improve governance capacity to react to unforeseen risks and to lead processes that require systemic response. As systems change, it is increasingly important to understand how the changes that do occur feed back into governance practices, as this will have implications for the system's ability to continue absorbing, adapting and transforming.

\section{How is legitimacy created?}

Legitimate health systems are accepted through de facto and de jure processes and trusted by communities, who have the power to influence the system. ${ }^{3}$ After COVID-19, health systems need to create consistent and institutionalised channels to incorporate the political and socioeconomic context. The power of competing actors and interests within the health system and between technical and political decision makers are all likely to affect legitimacy. With COVID-19, health system actors, politicians, other decision-makers and the general public are receiving an ever-changing flow of information and evidence as COVID-19 circumstances change. This unprecedented global awareness and general knowledge of COVID-19 has shaped political actions and population beliefs in 
health expertise, bringing the health system's response to COVID-19 into sharp relief for communities. Community experiences with corruption and accountability and their perceptions of actors with power who are outside of the health system are also likely to influence trust in the health system. ${ }^{24}{ }^{25}$ Their trust in the system and actors can directly impact the system's ability to respond to shocks. At present, mistrust is at the root of COVID-19 vaccine hesitancy, a barrier which will force health systems to adapt if countries are to reach herd immunity. The pandemic highlights the importance of clear communication to build and maintain trust in the population and the role of information and evidence in shaping legitimacy. Health systems will need to understand the internal and external mechanisms that generate legitimacy and will need to adapt to changing levels of trust if they are to effectively respond to shocks like COVID-19. For example, sound communication strategies could reinforce legitimacy and could constitute an important space for collaboration between public and private sectors and the community, while reinforcing systems thinking for resilience in social systems like health systems.

\section{In what ways do the private and voluntary sectors influence health system resilience?}

Existing health system resilience research has focused on the public sector, yet the private and voluntary sectors are likely to play vital roles in the system's capacity for resilience and its preparedness and response to shocks and stresses. This requires understanding how the public, private and voluntary sectors of the health system interact during shocks, as well as the influence on resilience of the different governance structures between the public and private sector of the system, such as the need for increased coordination in highly segmented health systems. The private sector should not be limited to private for-profit providers and healthcare services but extended to corporate services and interventions for health. The COVID-19 pandemic has shown the far-reaching influence of broader structures like global markets on health system capacities, like the supply chain failures leading to personal protective equipment shortages. Future research should include not-for-profit and faith-based organisations, the biomedical industry, the supply chain and logistics, the tech industry, regional markets and other private sector actors, as they all are likely to help or hinder the health system's capacity to overcome adaptive challenges and manage resilience.

\section{Approaches to researching health systems resilience}

Longitudinal studies, comparative case studies and forwardlooking learning sites are essential to answering the questions above. We must consider innovative ways of approaching resilience research to understand how a health system can respond to a crisis and the processes and behaviour enabling change to happen. This entails also combining public health and social sciences research methods. Although difficult to measure, approaches will need to better include soft-issues like power, trust and social capital. Research will also need to explore how health systems have developed and changed over time if we are to understand the dynamics of health systems and explain the reasons for changes within the system. Understanding changes over time can illuminate the factors, processes and pathways that have led to a system's capacity for resilience, show the short- and long-term consequences of change in the system, and further clarify the boundaries between absorptive, adaptive and transformative capacities.

It is time to reconsider how health system resilience research is produced. We acknowledge the difficulty in funding, conducting, and disseminating independent research on processes and systems over time. Still, we believe that a bottom-up, cocreation and coproduction approach to embedded research, associating researchers, policy-makers, politicians, practitioners and the public from various settings can advance health systems resilience research is key ${ }^{26}$ Research and researchers need to be closer to the health system's response structures and closer to people in power, such as national, multilateral and bilateral funding bodies and policy-makers, while maintaining independence. ${ }^{27}$ Coproduction approaches inherently create spaces for mutual knowledge exchange across researchers and policy-makers throughout the entire research process, starting at study design. In these ways, research can provide workable solutions to policy and practice questions that are most relevant and impactful. By using a more inclusive approach to how we develop and conduct research, we can begin to build the strategies and concrete findings that can support local and national health system practitioners, the ultimate end users of resilience research and help to develop resilience thinking capacity across regions.

\section{CONCLUSION}

The COVID-19 pandemic has been a stark reminder of the risks that health systems and populations face. It has shown the limitations of existing systems, such as the scale up of emergency health service systems, maintaining services for routine and chronic health needs, incorporating wide-scale diagnostic testing into health services, failing supply chain systems to source supplies like reagents for diagnostic tests, personal protective equipment and sanitiser and the roll-out of large-scale vaccination programmes. It has highlighted the importance of tying systems research and the complexity of the environment in which health systems operate with public health practice. ${ }^{28}$ Developing research on resilience as a health system ability that is methodologically sound and policy relevant is crucial to strengthen health systems.

We believe a cohesive agenda and cocreated and coproduced approach to health system resilience research that builds on existing findings and bridges conceptual gaps, and associates researchers, policy-makers and practitioners from various settings, can advance health systems resilience research. This paper is a starting point for a 
more comprehensive agenda and action on cocreation and coproduction.

\section{Author affiliations}

${ }^{1}$ Department of Global Public Health, Karolinska Institute, Stockholm, Sweden ${ }^{2}$ Geneva Centre of Humanitarian Studies, Faculty of Medicine, University of Geneva and Graduate Institute of International and Development Studies, Geneva, Switzerland

${ }^{3}$ Department of Health Policy and Administration, University of the Philippines Manila, Manila, Philippines

${ }^{4}$ Swiss Tropical and Public Health Institute, Basel, Switzerland

University of Basel, Basel, Switzerland

${ }^{6}$ Alliance for Health Policy and Systems Research, World Health Organization, Geneva, Switzerland

${ }^{7}$ World Health Organization, Geneva, Switzerland

${ }^{8}$ Center for Emerging Infectious Diseases Policy and Research, Boston University, Boston, Massachusetts, USA

${ }^{9}$ Alliance For Health Policy and System Research, Geneva, Switzerland

${ }^{10}$ Department of Economics, University of Buenos Aires, Buenos Aires, Argentina

${ }^{11}$ Center for the Study of State and Society (CEDES), Buenos Aires, Argentina

${ }^{12}$ Unisanté, Center for Primary Care and Public Health, University of Lausanne, Lausanne, Switzerland

${ }^{13}$ CEPED, Institute for Research on Sustainable Development, IRD-Université de Paris, ERL INSERM SAGESUD, Paris, France

${ }^{14}$ Centre for Health Systems and Policy Research, Ghana Institute of Management and Public Administration, Accra, Ghana

${ }^{15}$ Global Studies Institute, University of Geneva, Geneva, Switzerland

Twitter Karl Blanchet @BlanchetKarl, Daniel Cobos Muñoz @Daniel_Cobos_PH, Kara N Durski @KaraDurski, Robert Marten @martenrobert, Valery Ridde @ValeryRidde and Fabrizio Tediosi @fabrizio2570

Contributors DDS, KB and FT designed and led the workshop and wrote the first draft of the manuscript. All authors contributed to the workshop and to revisions of the manuscript. All authors gave final approval of the manuscript.

Funding The work was supported by the initiative "Foster Inter-University Initiatives and Collaborations" of the Swiss School of Public Health https:// ssphplus.ch/.

Competing interests None declared.

Patient consent for publication Not required.

Provenance and peer review Not commissioned; externally peer reviewed.

Data availability statement Data sharing is not applicable as no data was generated or analysed for this manuscript.

Open access This is an open access article distributed in accordance with the Creative Commons Attribution Non Commercial (CC BY-NC 4.0) license, which permits others to distribute, remix, adapt, build upon this work non-commercially, and license their derivative works on different terms, provided the original work is properly cited, appropriate credit is given, any changes made indicated, and the use is non-commercial. See: http://creativecommons.org/licenses/by-nc/4.0/.

\section{ORCID iDs}

Dell D Saulnier http://orcid.org/0000-0001-7761-0737

Karl Blanchet http://orcid.org/0000-0003-0498-8020

Kara N Durski http://orcid.org/0000-0003-1456-626X

Robert Marten http://orcid.org/0000-0002-2416-2309

Valery Ridde http://orcid.org/0000-0001-9299-8266

Didier Wernli http://orcid.org/0000-0002-1751-1961

Fabrizio Tediosi http://orcid.org/0000-0001-8671-9400

\section{REFERENCES}

1 Kruk ME, Myers M, Varpilah ST, et al. What is a resilient health system? Lessons from Ebola. Lancet 2015;385:1910-2.

2 Bene C, Wood RG, Newsham A. IDS Working Paper 405. Resilience: New Utopia or New Tyranny? Reflection about the potentials and limits of the concept of resilience in relation to vulnerability reduction programmes. Institute of Development Studies, 2012.
3 Blanchet K, Nam SL, Ramalingam B, et al. Governance and capacity to manage resilience of health systems: Towards a new conceptual framework. Int J Health Policy Manag 2017;6:431-5.

4 Ridde V, Gautier L, Dagenais C, et al. Learning from public health and hospital resilience to the SARS-CoV-2 pandemic: protocol for a multiple case study (Brazil, Canada, China, France, Japan, and Mali). Health Res Policy Syst 2021;19:76.

5 Haldane V, De Foo C, Abdalla SM, et al. Health systems resilience in managing the COVID-19 pandemic: lessons from 28 countries. Nat Med 2021;27:964-80.

6 Turenne CP, Gautier L, Degroote S, et al. Conceptual analysis of health systems resilience: a scoping review. Soc Sci Med 2019;232:168-80.

7 de Savigny D, Blanchet K, Adam T. Applied systems thinking for health systems research: a methodological handbook. Geneva, Switzerland: Open University Press, 2017.

8 Biddle L, Wahedi K, Bozorgmehr K. Health system resilience: a literature review of empirical research. Health Policy Plan 2020;35:1084-109.

9 Topp SM. Power and politics: the case for linking resilience to health system governance. BMJ Glob Health 2020;5:e002891.

10 Kutzin J, Sparkes SP. Health systems strengthening, universal health coverage, health security and resilience. Bull World Health Organ 2016;94:2.

11 Haldane V, Ong S-E, Chuah FL-H, et al. Health systems resilience: meaningful construct or catchphrase? The Lancet 2017;389:1513.

12 van de Pas R, Ashour M, Kapilashrami A, et al. Interrogating resilience in health systems development. Health Policy Plan 2017;32:iii88-90.

13 Hanefeld J, Mayhew S, Legido-Quigley $\mathrm{H}$, et al. Towards an understanding of resilience: responding to health systems shocks. Health Policy Plan 2018;33:355-67.

14 Saulnier DD, Hean H, Thol D, et al. Staying afloat: community perspectives on health system resilience in the management of pregnancy and childbirth care during floods in Cambodia. BMJ Glob Health 2020;5:e002272.

15 Sturmberg JP, Bircher J. Better and fulfilling healthcare at lower costs: the need to manage health systems as complex adaptive systems. F1000Res 2019;8:789.

16 Kwamie A, Ha S, Ghaffar A. Applied systems thinking: unlocking theory, evidence and practice for health policy and systems research. Health Policy Plan.

17 Saulnier D, Tediosi F, Blanchet K. Re-evaluating our knowledge of health system resilience following COVID-19: lessons from the pandemic and applied health system resilience research. Int $\mathrm{J}$ Health Policy Manag [Submitted] 2021.

18 Wernli D, Clausin M, Antulov-Fantulin N. Governance in the age of complexity: building resilience to COVID-19 and future pandemics. Geneva, Switzerland: Geneva Science-Policy Interface Policy Brief, 2021.

19 Martineau FP. People-centred health systems: building more resilient health systems in the wake of the Ebola crisis. Int Health 2016;8:307-9.

20 Ling EJ, Larson E, Macauley RJ, et al. Beyond the crisis: did the Ebola epidemic improve resilience of Liberia's health system? Health Policy Plan 2017;32:iii40-7.

21 Kieny M-P, Evans DB, Schmets G, et al. Health-system resilience: reflections on the Ebola crisis in western Africa. Bull World Health Organ 2014;92:850.

22 Wilkinson A, Parker M, Martineau F, et al. Engaging 'communities': anthropological insights from the West African Ebola epidemic. Philos Trans R Soc Lond B Biol Sci 2017;372:20160305.

23 Gilson L, Lehmann U, Schneider H. Practicing governance towards equity in health systems: LMIC perspectives and experience. Int $J$ Equity Health 2017;16:171.

24 García PJ. Corruption in global health: the open secret. The Lancet 2019;394:2119-24.

25 Brinkerhoff DW. Accountability and health systems: toward conceptual clarity and policy relevance. Health Policy Plan 2004;19:371-9.

26 Redman S, Greenhalgh T, Adedokun L, et al. Co-production of knowledge: the future. BMJ 2021;372:n434.

27 Durski KN, Osterholm M, Majumdar SS, et al. Shifting the paradigm: using disease outbreaks to build resilient health systems. BMJ Glob Health 2020;5:e002499.

28 Gilson L, Marchal B, Ayepong I, et al. What role can health policy and systems research play in supporting responses to COVID-19 that strengthen socially just health systems? Health Policy Plan 2020;35:1231-6. 